\title{
Demodex spp Distribution in Patients with Alcohol Abuse
}

\author{
Serpil Şener ${ }^{1}$, Ülkü Karaman ${ }^{2}$, Nihal Altunış1k ${ }^{1}$, Gülbahar Saraç${ }^{1}$, Birgül Cumurcu ${ }^{3}$, Gülden Hakverdi ${ }^{4}$ \\ ${ }^{1}$ Inonu University, Faculty of Medicine, Department of Dermatology, Malatya, Turkey \\ ${ }^{2}$ Ordu University, Faculty of Medicine, Department of Parasitology, Ordu, Turkey \\ ${ }^{3}$ İnönü University, Faculty of Medicine, Department of Psychiatry, Malatya, Turkey \\ ${ }^{4}$ Ege University, Faculty of Medicine, Department of Biostatistics and Medical Informatics, İzmir, Turkey
}

Received: 05 December 2019, Accepted: 23 December 2019, Published online: 31 December 2019

(C) Ordu University Institute of Health Sciences, Turkey, 2019

\begin{abstract}
Objective: Demodex is an ectoparasite that can infest the human body. The infestation can progress rapidly when the immune system is suppressed. The condition has also been reported to be more common in subjects with alcohol abuse because of the associated immune system abnormalities and decreased hygiene. Our aim in this study was to determine whether a relationship was present between Demodex spp. infestation and alcohol abuse

Methods: A total of 26 patients diagnosed with alcohol abuse according to DSM-5 at the psychiatry outpatient department and 24 age- and gender-matched healthy volunteers who met the study inclusion criteria were included in the study. A standard superficial skin biopsy (SSSB) was used in the diagnosis of Demodex folliculorum. The compliance of the numeric variables with the normal distribution was investigated with the Shapiro-Wilk test. The data were presented as mean, standard deviation and percentages Results. A significant relationship was found between Demodex presence and alcohol abuse ( $\mathrm{p}=0.001)$. The relationship was also significant when patients with both alcohol abuse and smoking were investigated $(\mathrm{p}<0.001)$.

Conclusion: The Demodex spp. infestation incidence may be increased in patients with alcohol abuse. We recommend providing the relevant treatment especially for erythematous and itchy facial lesions in these patients as Demodex spp. can be opportunistic pathogens.
\end{abstract}

Key words: Demodex, Alcohol abuse, smoking, addiction and demodex.

Suggested Citation: Sener S, Karaman U, Altunisik N, Sarac G, Cumurcu B, Hakverdi G. Demodex spp Distribution in Patients with Alcohol Abuse. Middle Black Sea Journal of Health Science, 2019; 5(3):246-251

\section{Address for correspondence/reprints:}

Ülkü Karaman

Telephone number: +90 (553) 6185245

E-mail: ulkukaraman44@hotmail.com

DOI: $10.19127 / \mathrm{mbsjohs.} 655707$

\section{Introduction}

Demodex is from the Demodicidae family of the Trombidiformes genus and 8 species and 16 types that are parasitic in mammals are known. Only two types of Demodex can infest the human body. Demodex folliculorum (D. folliculorum) can be present in hair follicles by itself or in groups. Demodex brevis (D. brevis) is found in sebaceous glands and is usually detected by itself. The parasite can be found on the face, scalp, neck, ears, chest, nipples and genital region, in order of incidence. It has been reported to spread by close contact, shaking hands and kissing (Karaman et al. 2016; Turan et al., 2017). 
The density of Demodex mites in $\mathrm{cm} 2$ in the normal skin is less than 5 . They can cause skin disorders when present in numbers over 5 in a pilosebaceous unit (Yun et al., 2017). The parasite incidence has been reported to be influenced by the skin $\mathrm{pH}$, moisture, temperature and personal hygiene, all of which affect the density (Tilki et al., 2017). The parasite may also play an important role in the pathogenesis of various disorders such as rosacea, acne vulgaris, dermatitis and blepharitis (Yun et al. 2017).). Routine diagnostic methods such as cellophane slides, skin scraping, punch biopsy of lash samples and standard superficial skin biopsy are used in the diagnosis (Aycan et al., 2006; Kockaya, 2016; Yun et al. 2017).

Demodex infestation can show severe progression in immunosuppressed patients (Ozcelik, 2007). Chronic alcohol use has also been reported to have a negative effect on immune system functions (Crews, 2006; Romeo, 2007). Demodex infestation can be more common in subjects with alcohol abuse as immune system abnormalities and decreased hygiene can be present (Kockaya, 2016). A literature survey has revealed that the epidemiology of Demodex species has been studied in subjects with alcohol abuse. We therefore tried to determine whether a relationship was present between Demodex spp. infestation and subjects diagnosed with alcohol abuse in the psychiatry outpatient department.

\section{Methods}

Ethics Committee permission was obtained before the study started. A consent form was obtained from the patients who were attending the psychiatry outpatient department for alcohol abuse and who accepted to provide samples. A total of 26 subjects with alcohol abuse and 24 healthy volunteers were included in the study. The healthy volunteers were age- and gender-matched with the patients and did not smoke or use alcohol or any other substance. Those with known systemic or dermatologic diseases were not included in the study

A standard superficial skin biopsy (SSSB) was used in the diagnosis of $\mathrm{D}$. folliculorum. The method is non-invasive and is performed by taking the surface layer of the skin and the follicle content with the help of cyanoacrylate adhesive (Marks and Dawber, 1971). A Demodex density over $5 / \mathrm{cm} 2$ with SSSB is reported to be significant for the final diagnosis (Marks and Dawber, 1971; Erbagci and Ozgoztasi, 1998). In practice, a drop of cyanoacrylate adhesive is placed on a clean slide. Mild pressure is applied with the slide to the relevant facial region and the adhesive contacts the face for one minute. The slide is then withdrawn with a single movement and 2 to 3 drops of Hoyer solution is placed on the sample. The sample is then covered with a coverslip and examined under the light microscope at $4 \mathrm{x}$ and 10x magnification. Five or parasites in a one $\mathrm{cm} 2$ area was accepted as proof of infestation (demodicidosis) in this study.

\section{Statistical evaluation}

The IBM SPSS Statistics 25.0 Program was used. The compliance of the numeric variables with the normal distribution was investigated with the Shapiro-Wilk test. The data were presented as mean, standard deviation and percentages. The Chisquare test was used for categorical data. The independent two-sample $t$ test was used for the comparison of groups for numeric variables.

\section{Results}

The rate of parasite detection in the subjects with alcohol abuse and the normal volunteers is presented in table 1 .

Table 1. Demodex spp. Distribution Rates

\begin{tabular}{|c|c|c|c|c|c|}
\hline & & & Patient & Control & p* \\
\hline \multirow{3}{*}{\multicolumn{2}{|c|}{ Demodex }} & Present & $13(50 \%)$ & $2(8.3 \%)$ & \multirow{3}{*}{0.002} \\
\hline & & None & $13(50 \%)$ & $22(91.7 \%)$ & \\
\hline & & Total & $26(100 \%)$ & $24(100 \%)$ & \\
\hline \multirow{3}{*}{ Gender } & & Female & $2(15.38 \%)$ & $2(16.66 \%)$ & \multirow[t]{2}{*}{0,933} \\
\hline & & Male & $24(84.62 \%)$ & $22(83.34 \%)$ & \\
\hline & Group & $\mathbf{n}$ & Mean & Standard Deviation & $\mathbf{p}^{*}$ \\
\hline \multirow{3}{*}{ Age } & Patient & 26 & 44.69 & 9.785 & \multirow{2}{*}{0.626} \\
\hline & Control & 24 & 43.33 & 9.814 & \\
\hline & $\mathbf{N}$ & Minimum & Maximum & Mean & Std. Deviation \\
\hline Time(Year) & 26 & 1 & 40 & 18.12 & 11.476 \\
\hline
\end{tabular}

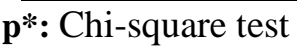


Table 2. Demographic Data of the Patient and Control Groups

\begin{tabular}{llrr}
\hline & & N & Yüzde (\%) \\
\hline \multirow{3}{*}{ Gender } & Male & 46 & 92.0 \\
& Female & 4 & 8.0 \\
& Total & 50 & 100.0 \\
\hline \multirow{3}{*}{ Demodex } & Yes & 15 & 30 \\
& No & 35 & 70 \\
& Total & 50 & 100.0 \\
\hline \multirow{3}{*}{ Smoking } & Yes & 23 & 46 \\
& No & 27 & 54 \\
& Total & 50 & 100 \\
Alcohol Abuse & Yes & 26 & 52 \\
& No & 24 & 48 \\
\hline \multirow{2}{*}{ Skin Findings (Patient } & Total & 50 & 100 \\
Group) & Yes & 17 & 34 \\
& No & 9 & 18 \\
\hline
\end{tabular}

Table 3. The distribution of Demodex according to alcohol abuse, smoking status and skin findings

\begin{tabular}{|c|c|c|c|c|c|c|c|c|}
\hline & & & Alco & & Smo & & Skin & \\
\hline & & & Yes & No & Yes & No & Yes & No \\
\hline & & Number & 13 & 22 & 25 & 10 & 7 & 6 \\
\hline & No & $\%$ & 37.1 & 62.9 & 71.4 & 28.6 & 53.8 & 46.2 \\
\hline & & Total \% & 26.0 & 44.0 & 50.0 & 20.0 & 26.9 & 23.1 \\
\hline Demodex & & Number & 13 & 2 & 2 & 13 & 2 & 11 \\
\hline & Yes & $\%$ & 86.7 & 13.3 & 13.3 & 86.7 & 15.4 & 84.6 \\
\hline & & Total \% & 26.0 & 4.0 & 4.0 & 26.0 & 7.7 & 42.3 \\
\hline & & Number & 26 & 24 & 27 & 23 & 9 & 17 \\
\hline Total & & $\%$ & 52.0 & 48.0 & 54.0 & 46.0 & 34.6 & 65.4 \\
\hline & & Total \% & 52.0 & 48.0 & 54.0 & 46.0 & 34.6 & 65.4 \\
\hline
\end{tabular}

Table 1 shows that Demodex was found in 13 $(50 \%)$ of the patients in the study (Figure 1). The parasite incidence rate was significantly higher in the alcohol abuse group than the control group $(\mathrm{p}=0.002)$. The mean age of the patients was $44.69 \pm 9.785$ year and the mean disease duration was $18.12 \pm 11.476$ years. The patient group consisted of 26 subjects and the control group of 24 subjects.

The demographic data of the subjects included in the study are presented in table 2 .

As seen in table 2, the study group consisted of 46 males and 4 females. The alcohol abuse group included $24(92.3 \%)$ males and $2(7.7 \%)$ females for a total of 26 patients. Among this group, the number of smokers was $23(88 \%)$ and the number of patients with a positive skin finding was 17 (65.4\%).

The distribution of Demodex in the study groups is presented in table 3 .

There was a significant relationship between Demodex and both alcohol abuse $(\mathrm{p}=0.001)$ and smoking $(\mathrm{p}<0.001)$.

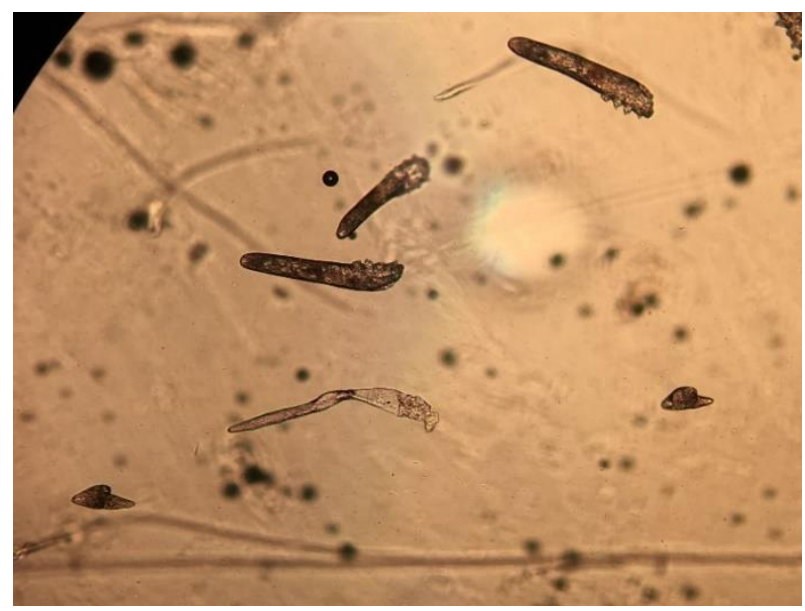

Figure 1. Demodex spp. adult larva and egg (10X).

\section{Discussion}

The Demodex infestation rate has been reported not to differ according to race and gender and the parasite to be widespread globally (Rufli et al., 1981). The rate varies according to age in healthy individuals and reaches $100 \%$ in the elderly (Rufli et al., 1981). Various studies have also reported that infestation is not observed in children in the absence 
of an immunosuppressive disorder and the incidence rate increases with age after puberty. (Karaman et al., 2014; Durmaz et al., 2015; Demirdag et al., 2016). Wang reported an infestation rate of $51.5 \%$ in 2248 patients aged 18 27 years in his 1848 study (Wang and $\mathrm{Hu}, 2001$ ). The mean age of the patients in the current study was $44.69 \pm 9.785$ years and Demodex was found in $13(50 \%)$. The incidence rate was significantly higher in the patient group than the control group $(\mathrm{p}=0.002)$.

We used the SSSB method to diagnose the parasite and the samples were evaluated immediately. The Hoyer solution used in the study has been reported to provide a clearer view of the mites in relevant studies, making it suitable for diagnostic use (Tilki et al., 2017). The diagnostic method used in this study can therefore considered to be quite effective in detecting the parasites.

Various studies have reported that Demodex spp. can infest every hair follicle in several regions of the body. However, the parasite density can be higher in the facial region and cheek than in the other regions (Erbagci and Ozgoztasi, 1998; Karaman et al., 2014; Durmaz et al., 2015; Demirdag et al., 2016). We chose the facial region for the sample as it has the highest incidence rate and the patients allowed only one sample to be taken. The prevalence range in healthy individuals is $6.7 \%-74 \%$ for $\mathrm{D}$. folliculorum, $11.1 \%-30.7 \%$ for $D$. brevis and $10.07 \%-74.7 \%$ for Demodex spp. (Tilki et al., 2017). The Demodex spp. incidence was found to be $8.3 \%$ in the control group in our study and this is similar to results from other studies.

Various studies on Demodex spp. incidence have evaluated Demodex epidemiology. A study from Sivas used SSSB and the eyelashes from 47 patients with chronic kidney failure and control subjects. D. folliculorum was found in the eyelash follicles of 6 patients and on the face of 12 patients. These rates were higher than found in the control group (Ozcelik et al., 2007). Inci et al. (2012) found D. folliculorum in $22.4 \%$ of the cancer patients and $3.2 \%$ of the control group with the SSSB method in 49 patients with urological cancer and 31 healthy controls. The parasite density in dialysis patients was found to be significantly higher than the control group in a study on 67 dialysis patients and 67 healthy individuals in Malatya (Karincaoglu et al., 2005). The infestation rate was $19.54 \%$ (Duzgun and Aytekin, 2007) in 87 hemodialysis patients in Diyarbakır, $28.9 \%$ in 45 patients receiving phototherapy. The rates were $12 \%$ in 41 patients with rheumatoid arthritis and $8 \%$ in 27 controls in another study from Afyonkarahisar (Ciftci et al., 2007) and $24.5 \%$ in 290 patients with various chronic diseases such as diabetes, renal failure, hypertension, hyperthyroid and cancer and $6 \%$ in 100 control subjects in Van (Tas et al., 2010). We found a Demodex positivity rate of $50 \%$ in this study.

Alcohol suppresses the immune system. Alcoholic pathology is known to impair the body's cytokine balance and function. Cell immunity is insufficient in moderate and heavy drinkers due to the direct toxic effect of alcohol on the bone marrow. The number and function of $\mathrm{T}$ cells are decreased in chronic addicts. Similarly, the number and function of granulocytes are also decreased, together with chemotaxis and phagocytosis. The humoral immune system is affected less than the cellular immune system. However, heavy drinkers experience shows a decreased primary antigen reaction to antibody production (Crews et al., 2006; Kockaya et al., 2016)

It has been reported that the immune status of the host can also influence the Demodex infestation rate. On the other hand, the number of mites living commensally in healthy individuals may increase as with opportunistic pathogens in diseases such as AIDS and malignancies that cause immune dysfunction (Jansen et al., 2001; Aquilina et al., 2002; Akilov and Mumcuoglu, 2004; Inci et al., 2012). Chovatiya et al. (2016) found an increased Demodex spp. prevalence in conditions weakening the immune system such as organ transplantation. Another study has reported that Demodex infestation can be more common in diabetic patients as the disease may increase the possibility of an immunosupressed state (Akdeniz et al., 2002). Disorders compromising the immune system such as cancer, chemotherapy, chronic renal failure, and organ transplantation have been reported to potentially cause D. folliculorum infestation (Bastemir et al., 2015). Similarly, Zeytun and Olmez (2017) found that immunosuppression can significantly increase Demodex density and that COAD patients have higher rates of Demodex infestation than control subjects. They reported that Demodex infestation can develop in patients receiving immunosuppressive treatment and that this should be taken into account. We found a positive association between Demodex presence and alcohol abuse $(\mathrm{p}=0.001)$ and smoking $(\mathrm{p}<0.001)$ in this study.

In conclusion, the Demodex spp. infestation incidence can increase in patients with alcohol abuse and should be considered. Patients with 
alcohol abuse are occasionally admitted to psychiatric clinics for treatment. Nurses and ancillary health care staff should be careful in terms of erythema and papulopustular lesions and request a dermatology consultation when necessary. We suggest considering that Demodex species can be opportunistic pathogens especially in erythematous, itchy facial lesions in this patient group and providing the necessary treatment.

Ethics Committee Approval: Ethics committee approval was received for this study from Inonu Clinical Research Ethics Committee of InonuUniversity (Ethichs No: 2019-01-07).

Peer-review: Externally peer-reviewed.

Author Contributions: Concept - SS, ÜK, NA, BC, GS, GH; Design SS, ÜK, NA, GS; Supervision SS, ÜK, Materials - SS, NA, BC, GS ; Data Collection and/or Processing - SS, NA, BC, GS,Analysis and/or Interpretation - SS, ÜK, GH; Literature Review - GE; Writing - SS, ÜK, GH; Critical Review - SS, ÜK, GH;

Conflict of Interest: No conflict of interest was declared by the authors.

Financial Disclosure: The authors declared that this study has /hasn't received no financial support.

\section{References}

Akdeniz S, Bahceci M, AK Tuzcu, Harman M, Alp $\mathrm{S}$, Bahceci S. İs demodex folliculorum larger in diabetic patients?. J Europ Acad Dermatol Venereol 2002;16 (5): 539.

Akilov OE, Mumcuoglu KY. İmmune response in demodicidosis. J Eur Acad Dermatol Venereol 2004;18:440-4.

Aquilina C, Viraben R, Sire S. Ivermectinresponsive Demodex infestation during human immunodeficiency virus infection. Dermatology 2002 205:394-7.

Aycan O, Otlu H, Karaman U, Daldal N, Atambay M. Frequency of Demodicosis in Various Patient and Age Groups. Turkish Society for Parasitology. 2007;31:1158.

Bastemir S, Ermertcan A, Nese N, Aydogdu I, Yereli K, Ozbilgin A. Hodgkin Lenfomali Bir Hastada Demodex folliculorum Enfestasyonu: Bir Olgu Sunumu. Turk Mikrobiyol Cem Derg 2015; 45(3):149-152

Chovatiya RJ, Colegio OR. Demodicosis in renal transplant recipients. Am J Transplant 2016;16:712-6.
Ciftci IH, Dundar U, Cetinkaya Z, Kulas M, Kiyildi $\mathrm{N}$, Turel A, et al. Demodex folliculorum in patients with rheumatoid arthritis. Acta Parasitol 2007;52: 70-3

Crews FT, Bechara R, Brown LA, Guidot DM, Mandrekar P, Oak S et al. Cytokines and alcohol. Alcohol Clin Exp Res. 2006;30:720-30.

Demirdag HG, Ozcan H, Gursoy S. The effects of sebum configuration on Demodex spp. density. Turk J Med Sci 2016; 46: 1-7

Durmaz S, Yula E, Aycan Kaya O, Aksoy Gokmen A, Kilinc C, Atambay $M$, et al. Sociodemographic characteristics of patients with Demodex brevis and Demodex folliculorum infestation and its association with rosacea and Behcet's disease. Biomed Res 2015; 26: 549-55.

Duzgun OY, Aytekin S. Comparison of Demodex folliculorum density in haemodialysis patients with a control group. J Eur Acad Dermatol Venereol 2007;21: 480-3.

Erbagci Z, Ozgoztasi O. The significance of Demodex folliculorum density in rosacea. International Journal of Dermatology 1998;37(6):421-5.

Inci M, Kaya OA, Inci M, Yula E, Gokce H, Rifaioglu MM, Demirtas O, Yengil E. İnvestigating Demodex folliculorum in patients with urological cancer. Turkish Society for Parasitology.2012; 36:208-10

Jansen T, Kastner U, Kreuter A, Altmeyer P. Rosacea-like demodicidosis associated with acquired immunodeficiency syndrome. $\mathrm{Br} \mathrm{J}$ Dermatol 2001; 144: 139-42.

Karaman U, Koloren Z, Enginyurt O, Colak C. Prevalence of demodex ectoparasites among humans in Ordu province in Turkey. Southeast Asian J Trop Med Public Health. 2016;47(2):207-13.

Karaman U, Koloren Z, Enginyurt O, Ozer A. The Epidemiology of Demodex mites at the College Students Living in Dormitories in the City of Ordu. Turkiye Parazitol Derg 2014; 38: 166-71.

Karincaoglu Y, Esrefoglu Seyhan M, Bayram N, Aycan O, Taskapan H. Incidence of Demodex folliculorum in patients with end stage chronic renal failure. Ren Fail 2005; 27: 495-9.

Kockaya MH, Kaya OA, Copoglu US, Elmacioglu S. Prevalence of Demodex spp among alcoholdependent patients. Cukurova Med J 2016;41(2):259-263. 
Marks R, Dawber RPR. Skin surface biopsy: an improved technique for the examination of the horny layer. British journal of Dermatology 1971;84(2):117-23

Ozcelik S, Sumer Z, Degerli S, Ozyazici G, Hayta $\mathrm{SB}$, Akyol M et al. The incidence of Demodex folliculorum in patients with chronic kidney deficiency. Turkish Society for Parasitology. 2007;31:66-8.

Romeo J, Warnberg J, Nova E, Diaz LE, GonzalezGross M, Marcos A. Changes in the immune system after moderate beer consumption. Ann Nutr Metab. 2007;51:35966.

Rufli T, Mumcuoglu Y, Cajacob A, Buchner S: D. folliculorum: aetiopathogenesis and therapy of rosacea and perioral dermatitis (author's transl). Dermatologica 1981;162:12-26.

Tas Cengiz, Z., Yilmaz H., Akdeniz, N., Cicek, M., Ozkol, $\mathrm{H}$ ve Calka, O. Associated of demodicosis with acne rosacea. Pakistan Journal of Medical Science 2010;26(3), 640-643.

Tilki E, Zeytun E, Dogan S. Prevalence and Density of Demodex folliculorum and Demodex brevis (Acari: Demodicidae) in Erzincan Province. Turkish Society for Parasitology.2017; 41: 80-6

Turan N, Kapicioglu Y, Sarac G. The Effect of Skin Sebum Sebum, pH, and Moisture on Demodex Infestation in Acne Vulgaris and Rosacea Patients. Turkiye Parazitol Derg.2017;41(3):143-147.

Wang Y, Hu Q: Investigation on the prevalence of human demodex among 2248 medical students in inner Mongolia. Zhongguo Ji Sheng Chong Xue Yu ji Sheng Chong Bing Za Zhi 2001;19:239-40.

Yun CH, Yun JH, Baek JO, Roh JY, Lee JR. Demodex Mite Density Determinations by Standardized Skin Surface Biopsy and Direct Microscopic Examination and Their Relations with Clinical Types and Distribution Patterns. Ann Dermatol. 2017 ;29(2):137-142.

Zeytun E, Olmez H. Demodex (Acari: Demodicidae) Infestation in Patients with $\mathrm{KOAH}$, and the Association with Immunosuppression. Erzincan University Journal of Science and Technology. 2017;10(2), 220-231. 